\title{
Aortic valve calcification is subject to aortic stenosis severity and the underlying flow pattern
}

\author{
Verena Veulemans ${ }^{1}$ (D) Kerstin Piayda ${ }^{1} \cdot$ Oliver Maier $^{1} \cdot$ Georg Bosbach $^{1} \cdot$ Amin Polzin $^{1} \cdot$ Katharina Hellhammer $^{1}$. \\ Shazia Afzal ${ }^{1}$ - Kathrin Klein ${ }^{1} \cdot$ Lisa Dannenberg $^{1}$ - Saif Zako ${ }^{1}$. Christian Jung ${ }^{1}$ - Ralf Westenfeld ${ }^{1}$ - Malte Kelm ${ }^{1,2}$. \\ Tobias Zeus $^{1}$
}

Received: 9 March 2020 / Accepted: 28 August 2020 / Published online: 7 September 2020

(c) The Author(s) 2020

\begin{abstract}
Sex- and flow-related aortic valve calcification (AVC) studies are still limited in number, and data on the exact calcium quantity and distribution are scarce. Therefore, we aimed to (1) re-define the best threshold of AVC load to distinguish severe from moderate aortic stenosis (AS) in common AS entities and to (2) evaluate differences in the aortic annulus and left ventricular outflow tract (LVOT) calcium load. Nine hundred and thirty-eight patients with contrast-enhanced cardiac MSCT and moderate-to-severe aortic stenosis (AS) were retrospectively enrolled. Patients with severe AS $\leq 1.0 \mathrm{~cm}^{2}(n=841)$ were further separated into three AS entities: high gradient (HGAS, $n=370,44.0 \%$ ), paradoxical low gradient (pLGAS, $n=333,39.6 \%$ ), and classical low gradient (LGAS, $n=138,16.4 \%$ ). AVC, leaflet, and LVOT calcification were quantified. Aortic valve calcification scores were highest in severe HGAS, and lower in severe pLGAS and classical LGAS. In all severity and AS entities, the non-coronary cusp (NCC) was the most calcified one. LVOT calcification was consistently comparable between gender and AS entities. Accuracy of logistic regression was the highest in HGAS (male vs. female: AVC > 2156 Agatston units (AU), c-index 0.76; vs. AVC > 1292 AU, c-index 0.85; or AVC density $>406 \mathrm{AU} / \mathrm{cm}^{2}$, c-index 0.82 ; vs. $>259 \mathrm{AU} / \mathrm{cm}^{2}$, c-index 0.86 ; each $p<0.0001^{*}$ ) to diagnose severe AS. AVC could only be used in men to differentiate between severe LGAS and moderate AS. Data from this retrospective analysis indicate that the NCC is subject to pre-dominant degeneration throughout gender, AS severity, and several AS entities. AVC was consistently comparable in severe pLGAS and classical LGAS, but only AVC in severe LGAS could sufficiently distinguish from moderate AS in men. LVOT calcification failed to be a reliable indicator of accelerating AS.
\end{abstract}

Keywords TAVR $\cdot$ TAVI $\cdot$ Aortic valve calcification $\cdot$ AS entities

$\begin{array}{ll}\text { Abbreviations } \\ \text { AS } & \text { Aortic stenosis } \\ \text { AVA } & \text { Aortic valve area } \\ \text { AU } & \text { Agatston units } \\ \text { LCC } & \text { Left coronary cusp }\end{array}$

Electronic supplementary material The online version of this article (https://doi.org/10.1007/s00380-020-01688-9) contains supplementary material, which is available to authorized users.

Verena Veulemans

verena.veulemanns@med.uni-duesseldorf.de

1 Division of Cardiology, Pulmonology and Vascular Medicine, Heinrich Heine University, Moorenstr. 5, 40225 Düsseldorf, Germany

2 CARID (Cardiovascular Research Institute Düsseldorf), Heinrich Heine University, Moorenstr. 5, 40225 Düsseldorf, Germany (p) LG (Paradoxical) low gradient

LVOT Left-ventricular outflow tract

NCC Non-coronary cusp

HG High-gradient

MSCT Multislice computed tomography

RCC Right coronary cusp

TTE Transthoracic echocardiography

\section{Introduction}

Aortic valve stenosis (AS) is the most common valvular heart disease in western countries with increasing prevalence [1]. Previous studies have demonstrated that the extent of aortic valve calcification (AVC), measured by multi-slice computed tomography (MSCT), correlates well with the hemodynamic severity of AS [2,3]. If compared to their 
male counterparts, woman tend to reach a higher degree of stenosis for the same amount of AVC burden, even after adjusting for body surface area and smaller aortic annulus size $[4,5]$. Furthermore, different AS entities are associated with discordant gradients from the aortic valve area (AVA), based on multiple valvular and non-valvular factors not depending on flow [4]. AVC quantification by MSCT helps to identify patients with severe AS: AVC > 1274 AU in women and $2065 \mathrm{AU}$ in men or with AVC density (indexed to annulus cross-sectional area) $>292 \mathrm{AU} / \mathrm{cm}^{2}$ in women and $>476 \mathrm{AU} / \mathrm{cm}^{2}$ in men are set to be the cut-off to distinguish between moderate and severe AS [4]. Those findings entered current guideline recommendations on the management of patients with valvular heart disease to improve clinical decision-making in patients with inconsistent diagnostic findings.

However, the definition of AS entities is subject to continuous modifications, and the existing sex- and flow-related AVC studies are limited to the number of studies in this context, and detailed information about calcium distribution and severity in patients with altered flow patterns are still missing. Therefore, we aimed to (1) re-define the best threshold of AVC load to distinguish severe from moderate AS in several AS entities and to (2) evaluate differences in the calcium load of the aortic annulus and left-ventricular outflow tract (LVOT).

\section{Methods}

\section{Study population}

We retrospectively enrolled 938 consecutive patients with moderate-to-severe tricuspid AS, who underwent diagnostic work-up for transcatheter aortic valve replacement between 2011 and 2019 at our heart center. Patients with moderateto-severe AS underwent MSCT if findings were heterogeneous and severe AS was clinically suspected. This especially applies to low-flow conditions and is in accordance with the current guideline recommendations for the treatment of patients with valvular heart disease. Those consider the calcium burden as a key decision-making factor if uncertainty in the grading of AS still exists after extensive work-up. AS severity was defined according to the existing guidelines [6]. Patients were further grouped into three AS entities, according to their flow pattern, as mentioned below. Patients with overt rheumatic valve disease, endocarditis, bicuspid morphology, or prior aortic valve replacement were excluded to account for comparability.

All patients provided written informed consent for the use of clinical, procedural, and follow-up data. The study procedures were in accordance with the Declaration of Helsinki and the institutional Ethics Committee of the Heinrich-Heine
University approved the study protocol (4080). The study is registered at clinical trials (NCT01805739).

\section{Statistical analysis}

The collected data included patient characteristics and imaging findings. Continuous data were described as mean with standard deviation, median or upper and lower $95 \%$ confidence interval, and interquartile ranges. Categorical variables were expressed by frequencies and percentages. Differences between men and women were analyzed with the use of the two-sided Student's $t$ test for continuous variables and the Fisher's exact test for categorical variable. To compare continuous variables without normal distribution, we used the Mann-Whitney $U$ test. The impact of sex was assessed by the interaction between sex and stenotic indexes in correlation, using transformed and untransformed AVC. One-way ANOVA with Tukey post hoc analysis was used to compare differences between more than two groups. Receiver-operating characteristic (ROC) analysis and the c-index (area under the curve, AUC) were used to identify the sensitivity and specificity of the AVC thresholds defined by AS severities and AS entities. The optimal cut-off values were defined by Youden's index, the point at which the value of "sensitivity + specificity -1 " was maximal.

The data analysis was performed using the statistical software SPSS (version 22.0, SPSS Inc., Chicago, IL, USA) and GraphPad Prism (version 6.0, Graphpad Software, San Diego, CA, USA). All statistical tests were two-tailed, and a value of $p<0.05$ was considered statistically significant.

\section{Imaging modalities}

\section{Transthoracic echocardiography (TTE)}

Transthoracic echocardiography was performed according to current expert recommendations. Severe high-gradient AS (HGAS) was defined as normal left-ventricular function $(\mathrm{LVF})>50 \%$ with high gradients (mean gradient $>40 \mathrm{mmHg}$ ) and a calculated AVA below $1.0 \mathrm{~cm}^{2}$. Paradoxical severe low-gradient AS (pLGAS) was defined as preserved LVF $>50 \%$ combined with a mean gradient $<40 \mathrm{mmHg}$ and a calculated AVA below $1.0 \mathrm{~cm}^{2}$. Classical severe low-gradient aortic stenosis (LGAS) was defined as reduced $\mathrm{LVF}<50 \%$ combined with a mean gradient $<40 \mathrm{mmHg}$ and a calculated AVA below $1.0 \mathrm{~cm}^{2}$. An AVA above $1.0-1.5 \mathrm{~cm}^{2}$ was defined as moderate AS. The true severity of AS was determined-especially in disconcordant borderline AS - by multiple validating tools according to the current recommendations (transesophageal echocardiography, cardiac magnetic resonance tomography, dobutamine stress echo if indicated, and 
MSCT-derived calcification load) and the final decision was made in the interdisciplinary heart team.

\section{D image analysis of MSCT}

Cardiac CT was routinely performed as native and contrast-enhanced multi-slice CT. CT data were obtained using a 128-slice, single source CT scanner with temporal resolution of $150 \mathrm{~ms}$ and a collimation of $128 \times 0.6 \mathrm{~mm}$ ("SOMATOM Definition AS+", Siemens Healthcare, Forchheim, Germany) according to TAVR-related standardized recommendations for CT image acquisition [7]. Images were analyzed in the diastolic phase. MSCT data were transferred to a dedicated workstation for three-dimensional (3D) volume-rendered reconstruction (3mensio Structural Heart ${ }^{\mathrm{TM}}$, Pie Medical Imaging BV, Maastricht, The Netherlands). Dimensions were determined with the use of workstation tools. The total AVC and calcium amount of the upper LVOT are expressed as recalculated Agatston units (AU) adapted from the calcium volume and subsequently divided by the MSCT-derived annulus area to estimate calcium density $\left(\mathrm{AU} / \mathrm{cm}^{2}\right)$. Every area section was handled separately (LVOT, AVC, leaflets) concerning the calcium amount and according to current recommendations. A pre-specific threshold of at least $600 \mathrm{HU}$ was set to account for the hyperdensity of the applied contrast medium as practicable approach according to current research data [8]. All MSCT-reconstructions and depending analyses were done by experienced level 3 readers. In general, upper and lower levels were defined according to the median and interquartile range.

\section{Results}

\section{Baseline characteristics}

443 male (47.2\%) and 495 female (52.8\%) patients were included. Male patients were younger $(80.4 \pm 5.8$ years vs $82.3 \pm 5.4$ years; $p<0.0001)$ and presented more often with concomitant coronary (CAD: $80.6 \%$ vs $64.9 \% ; p<0.0001$ ) and peripheral artery disease (PAD: $35.4 \%$ vs $23.0 \%$; $p<0.0001)$. Previous percutaneous coronary intervention (PCI: $47.0 \%$ vs $31.3 \% ; p<0.0001$ ), and coronary artery bypass grafting (CABG: $22.1 \%$ vs $4.5 \%$; $p<0.0001$ ) was more frequent in men than in woman. Left-ventricular ejection fraction was lower in male patients (LVEF: $52.0 \pm 13.4 \%$ vs $58.2 \pm 12.7 \%$; $p<0.0001$ ), accompanied by lower mean aortic valve gradients (dPmean: $35.7 \pm 14.9 \mathrm{mmHg}$ vs $38.6 \pm 16.7 \mathrm{mmHg} ; p=0.005)$. Further baseline characteristics are displayed in Supplemental material-Table 1.

\section{AVC thresholds according to AS severity}

Nine hundred and thirty-eight patients were separated into moderate (AVA $>1 \mathrm{~cm}^{2}, n=97 ; 10.3 \%$ ) and severe (AVA $\leq 1.0 \mathrm{~cm}^{2}, n=841 ; 89.7 \%$ ) AS. AVC scores were higher in male as compared to female patients in terms of the total calcium aortic valve burden, which was separated into the distinctive leaflet calcium burden, after recalculating in density proportion. AVC thresholds almost doubled if moderate AS was compared to severe AS (male: AVA $>1 \mathrm{~cm}^{2} / \leq 1.0 \mathrm{~cm}^{2}: 1365 \mathrm{AU}[827-2106]$ vs. $2245 \mathrm{AU}$ [1418-3340]; $p<0.0001 *$; female: AVA $>1 \mathrm{~cm}^{2} / \leq 1.0 \mathrm{~cm}^{2}$ : 642 AU [407-1124] vs. 1388 AU [772-2187]; $p<0.0001 *$; Table 1, Fig. 1a, b). In all groups, the non-coronary cusp (NCC) was the most calcified one (Fig. 1c, d). LVOT calcification, in total and recalculated as density proportion in AU/ $\mathrm{cm}^{2}$, was comparable throughout sex, but different in female patients concerning AS severity grading.

C-statistics (Supplemental material-Table 2) depicted an AVC > $2020 \mathrm{AU}$ in men (c-index 0.70, 95\% CI 0.62-0.77; $p<0.0001 *$ ) and $>1137 \mathrm{AU}$ in women (c-index $0.75,95 \%$ CI $\left.0.68-0.82 ; p<0.0001^{*}\right)$ or AVC density $>323 \mathrm{AU} / \mathrm{cm}^{2}$ in men (c-index $0.70,95 \%$ CI $0.63-0.78 ; p<0.0001^{*}$ ) and $>202 \mathrm{AU} / \mathrm{cm}^{2}$ in women (c-index $0.75,95 \% \mathrm{CI}$ $\left.0.69-0.82 ; p<0.0001^{*}\right)$ as the best threshold for diagnosis of severe AS. NCC density proportion performed best in female patients to identify severe AS, and LCC density proportion in male, respectively. LVOT calcification failed to be a reliable indicator for severe AS.

\section{AVC thresholds according to AS entity}

Eight hundred and forty-one patients with severe AS were further separated into HGAS $(n=370 ; 44.0 \%)$, pLGAS $(n=333 ; 39.6 \%)$, and LGAS $(n=138 ; 16.4 \%)$. Related hemodynamic profiles to the underlying flow patterns are displayed in Table 2. AVC scores were higher in male than in female patients and highest in HGAS (male vs. female: 3076 AU [2211-3884] vs. 1785 AU [1237-2720], $p<0.0001^{*} ; 551 \mathrm{AU} / \mathrm{cm}^{2}$ [401-707] vs. $424 \mathrm{AU} / \mathrm{cm}^{2}$ [292-625], $p=0.001^{*}$ ). AVC thresholds were comparable in pLG and LGAS throughout gender, including the total AU and density proportions (Table 2, Fig. 2a, b). In all groups, the NCC was the most calcified cusp.

C-statistics was most reliable in male and female patients presenting with HGAS (Table 3A): an AVC $>2156 \mathrm{AU}$ in men (c-index 0.76, 95\% CI 0.65-0.79; $p<0.0001 *$; sensitivity 65\%, specificity $79 \%$ ) and $>1292 \mathrm{AU}$ in women (c-index $0.85,95 \%$ CI $0.79-0.91 ; p<0.0001 *$; sensitivity $62 \%$, specificity $93 \%$ ) or AVC density $>406 \mathrm{AU} / \mathrm{cm}^{2}$ in men (c-index $0.82,95 \%$ CI $0.76-0.89 ; p<0.0001 *$; sensitivity $75 \%$, specificity $75 \%$ ) and $>259 \mathrm{AU} / \mathrm{cm}^{2}$ in women (c-index $0.86,95 \%$ CI $0.81-0.92$; $p<0.0001 *$; sensitivity $80 \%$, specificity $80 \%$ ) was found to be 
Table 1 Aortic stenosis quantification and associated calcification

\begin{tabular}{|c|c|c|c|c|c|}
\hline $\begin{array}{l}\text { Echocardiography and MSCT } \\
\mathrm{M}=\text { male } ; \mathrm{F}=\text { female }\end{array}$ & $\begin{array}{l}\text { AVA }>1.0 \mathrm{~cm}^{2} \\
(n=97) \\
\mathrm{M}=53 ; \mathrm{F}=44\end{array}$ & $p$ value & $\begin{array}{l}\text { AVA } \leq 1.0 \mathrm{~cm}^{2} \\
(n=841) \\
\mathrm{M}=390 ; \mathrm{F}=451\end{array}$ & $p$ value & $p_{\text {AS-severity }}$ \\
\hline M AVA, $\mathrm{cm}^{2}$ & $1.2 \pm 0.1$ & 0.069 & $0.7 \pm 0.2$ & $<0.0001^{*}$ & $<0.0001 *$ \\
\hline F AVA, $\mathrm{cm}^{2}$ & $1.1 \pm 0.1$ & & $0.7 \pm 0.2$ & & $<0.0001^{*}$ \\
\hline M dPmean, mmHg & $25.1 \pm 8.8$ & 0.359 & $37.1 \pm 15.0$ & $0.007^{*}$ & $<0.0001^{*}$ \\
\hline F dPmean, mmHg & $23.4 \pm 9.6$ & & $40.1 \pm 16.6$ & & $<0.0001^{*}$ \\
\hline M LVEF, \% & $49.5 \pm 14.6$ & $0.007 *$ & $52.2 \pm 13.3$ & $<0.0001^{*}$ & 0.292 \\
\hline F LVEF, \% & $60.5 \pm 14.5$ & & $58.0 \pm 12.5$ & & 0.334 \\
\hline M AVC, AU & 1365 [827-2106] & $<0.0001^{*}$ & 2245 [1418-3340] & $<0.0001^{*}$ & $<0.0001 *$ \\
\hline F AVC, AU & 642 [407-1124] & & 1388 [772-2187] & & $<0.0001 *$ \\
\hline M AVC density, AU/cm ${ }^{2}$ & $228[162-411]$ & $0.002 *$ & 414 [265-602] & $<0.0001^{*}$ & $<0.0001^{*}$ \\
\hline F AVC density, AU/cm ${ }^{2}$ & 157 [98-243] & & 322 [184-492] & & $<0.0001^{*}$ \\
\hline $\mathrm{M} N C C, \mathrm{AU}$ & 482 [283-1025] & $<0.0001^{*}$ & 868 [502-1364] & $<0.0001^{*}$ & $0.001^{*}$ \\
\hline F NCC, AU & 241 [89-433] & & $572[268-1042]$ & & $<0.0001 *$ \\
\hline M NCC density, AU/cm² & $95[54-173]$ & $0.001 *$ & $158[95-253]$ & $0.001 *$ & $<0.0001^{*}$ \\
\hline F NCC density, AU/cm² & 49 [25-104] & & 132 [65-235] & & $<0.0001 *$ \\
\hline $\mathrm{M} \mathrm{RCC}, \mathrm{AU}$ & $361[159-641]$ & $<0.0001^{*}$ & $641[362-1085]$ & $<0.0001^{*}$ & $<0.0001 *$ \\
\hline F RCC, AU & $170[48-360]$ & & 364 [200-652] & & $<0.0001^{*}$ \\
\hline M RCC density, AU/cm² & 65 [29-131] & $0.019^{*}$ & 113 [65-195] & $<0.0001^{*}$ & $<0.0001 *$ \\
\hline F RCC density, AU/cm ${ }^{2}$ & $45[12-76]$ & & 83 [44-155] & & $<0.0001 *$ \\
\hline M LCC, AU & $330[160-571]$ & $0.002 *$ & 607 [329-1032] & $<0.0001^{*}$ & $<0.0001 *$ \\
\hline F LCC, AU & 193 [79-309] & & $326[165-626]$ & & $0.0001^{*}$ \\
\hline M LCC density, AU/cm² & $65[36-100]$ & 0.055 & $111[61-178]$ & $<0.0001 *$ & $<0.0001^{*}$ \\
\hline F LCC density, AU/cm² & $46[21-71]$ & & 79 [38-145] & & $<0.0001^{*}$ \\
\hline M LVOT, AU & $15[0-157]$ & 0.202 & $32[0-176]$ & 0.820 & 0.661 \\
\hline F LVOT, AU & $4[0-75]$ & & 34 [2-189] & & $0.027^{*}$ \\
\hline M LVOT density, AU/cm² & $4[0-24]$ & 0.272 & $6[0-30]$ & 0.266 & 0.623 \\
\hline F LVOT density, AU/cm² & $1[0-19]$ & & $6[0-42]$ & & $0.023^{*}$ \\
\hline
\end{tabular}

Values are mean $\pm \mathrm{SD}$, median \pm interquartile range or $n(\%)$

$A V A$ aortic valve area, $A V C$ aortic valve calcification, $A U$ Agatston units, dPmean mean transvalvular gradient, $L C C$ left coronary cusp, $L V E F$ left-ventricular ejection fraction, LVOT left -ventricular outflow tract, $N C C$ non-coronary cusp, $R C C$ right coronary cusp

$* p<0.05$

the best threshold for diagnosis of severe AS if compared to overall moderate AS. In adaption to $\operatorname{LVF}(</>50 \%)$, detailed analysis of the calcium distribution in several flow patterns and moderate-to-severe AS showed that only AVC and leaflet calcification in men was able to differentiate between severe LGAS and moderate AS but not between severe pLGAS and moderate AS. For detailed information, please see Table 3B and the graphical abstract illustrating recommended aortic valve calcium scoring for an individualized diagnostic severity tool in different AS entities (Fig. 3).

\section{Discussion}

Existing sex- and flow-related AVC studies are limited to a small number of studies, and detailed information about calcium distribution and severity in patients with altered flow patterns is still missing. To our knowledge, this is the first study addressing AVC, including a proposal for the best thresholds to distinguish between moderate and severe AS in the three AS entities,

Our retrospective study revealed several new aspects:

1) The NCC was the most calcified cusp throughout gender, AS severity, and AS entities.

2) AVC thresholds were comparable in pLGAS and LGAS and did significantly differ from patients with HGAS, who presented with the highest calcium load.

3) LVOT calcification may be higher in severe and critical stenosis, but failed to be a reliable indicator for accelerating AS.

4) Only AVC in men was able to differentiate between severe LGAS and moderate AS. 

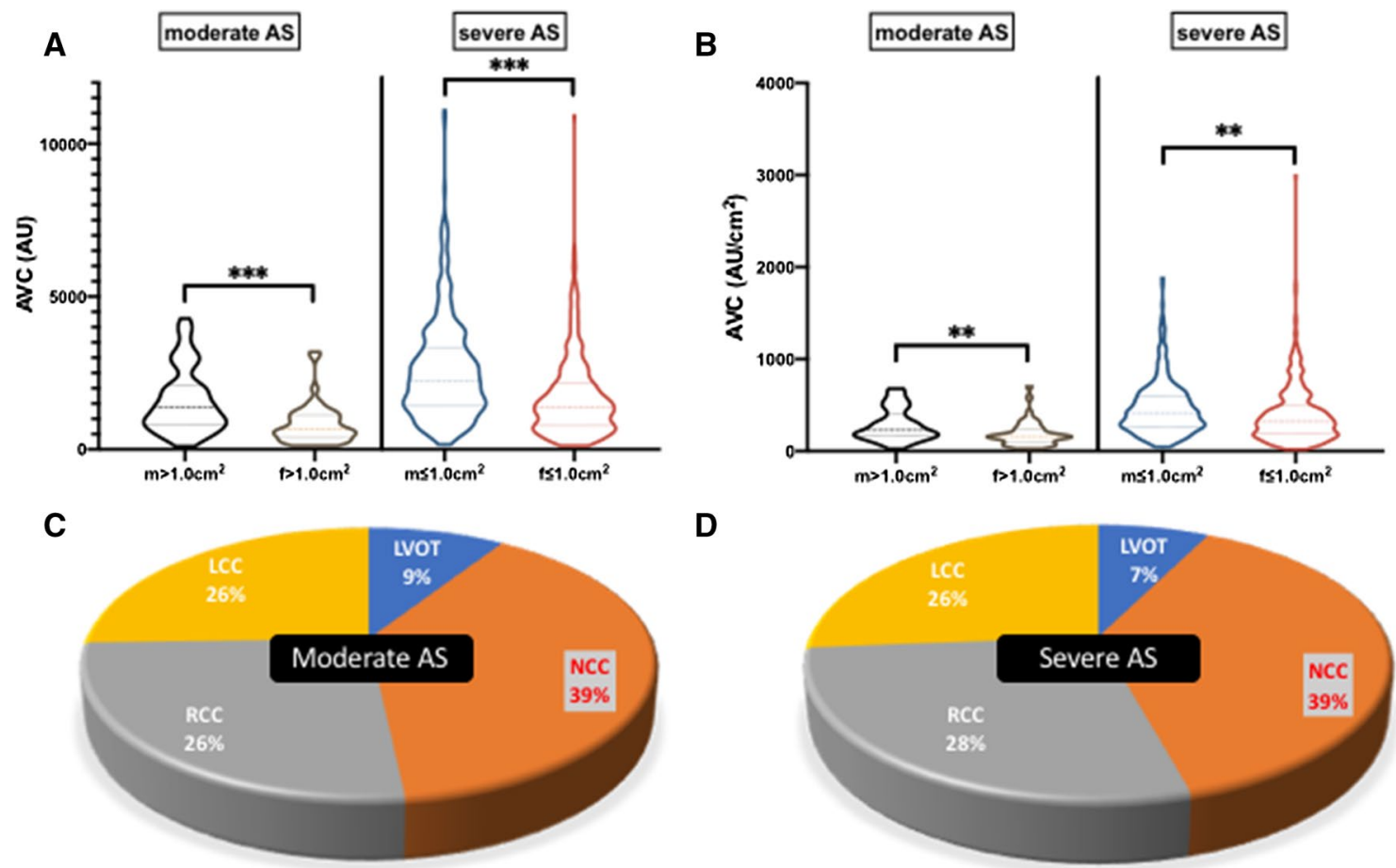

Fig. 1 a Total AVC in AU calculated in moderate and severe AS in comparison of male and female patients. b Calcium density $\left(\mathrm{AU} / \mathrm{cm}^{2}\right)$ proportions in comparison of male and female patients in moderate and severe AS. $\mathbf{c}$ Distribution of calcium load in moderate AS and $\mathbf{d}$ severe AS

\section{AVC thresholds according to AS severity}

It is well known that sex-specific AVC thresholds can help to identify severe AS and provide useful prognostic information. In this context, it has been shown that women, if compared to their male counterparts, tend to reach a higher degree of stenosis for the same amount of AVC burden, even after adjusting for body surface area and smaller aortic annulus $[4,5]$. AVC thresholds, including aortic valve leaflets and the LVOT, have not been separately addressed thus far.

\section{AVC thresholds (in total and as density proportion)}

According to previous multicenter trials and current guidelines, AVC scores are higher in male than in female patients regarding the calcium burden of the aortic valve in total, and separated into distinct leaflet calcification burden, after recalculating in density proportion. AVC thresholds increased about nearly twice AU from moderate-to-severe AS. NCC density proportion performed best in female and LCC density proportion best in male patients. In all groups of severity, the NCC was the most calcified cusp. Interestingly, LVOT calcification was consistently comparable concerning sex differences and AS severity in moderate and severe AS, and failed to be a reliable indicator for accelerating AS in borderline AS.

\section{AVC thresholds according to AS entity}

Previous studies have demonstrated that the extent of AVC correlates well with hemodynamic severity of AS [2, 3]. Furthermore, the three different AS entities are associated with discordant mean gradients apart from the AVA, based on multiple valvular and non-valvular factors independent of flow $[4,9,10]$. However, the definition of AS entities is subject to continuous modification in the setting of borderline or severe AS, which are not in line with the recommended pressure gradients and are likewise associated with different outcomes. Nowadays, pLGAS and LGAS estimate for nearly $15-30 \%$ of patients, so additional identifying parameters are strongly required, leading to an integrated approach, considering all available functional data together, in line with the clinical presentation.

\section{Discussion of AVC thresholds in different AS entities}

Patients with severe AS were separated into HG, pLG, and LGAS according to existing guidelines. As expected, in severe AS, AVC scores were higher in male than in female patients and highest in HGAS with a median AVC of $1785 \mathrm{AU}$ in women and $3076 \mathrm{AU}$ in men or an AVC density of $424 \mathrm{AU} / \mathrm{cm}^{2}$ in women and $551 \mathrm{AU} / \mathrm{cm}^{2}$ in men, and, therefore, higher than all-over severe AS independent from flow pattern. Interestingly, AVC thresholds 
Table 2 Hemodynamics and AVC in severe AS and in dependency of AS entity

\begin{tabular}{|c|c|c|c|c|c|c|c|}
\hline $\begin{array}{l}\text { Echocardiography and MSCT } \\
\mathrm{M}=\text { male; } \mathrm{F}=\text { female }\end{array}$ & $\begin{array}{l}\text { HGAS } \\
(n=370) \\
\mathrm{M}=156 ; \mathrm{F}=214\end{array}$ & $p$ value & $\begin{array}{l}\text { pLGAS } \\
(n=333) \\
\mathrm{M}=144 ; \mathrm{F}=189\end{array}$ & $p$ value & $\begin{array}{l}\text { LGAS } \\
\begin{array}{l}(n=138) \\
\mathrm{M}=90 ; \mathrm{F}=48\end{array}\end{array}$ & $p$ value & pANOVA \\
\hline M LVEF, \% & $55.2 \pm 12.9^{\#}$ & $0.002 *$ & $58.5 \pm 8.3^{\#}$ & $0.027 *$ & $35.9 \pm 10.1$ & 0.499 & $\begin{array}{l}<0.0001^{*} \\
\text { n.s. }\end{array}$ \\
\hline F LVEF, \% & $60.3 \pm 11.4^{\#}$ & & $61.1 \pm 8.5^{\#}$ & & $37.4 \pm 10.3$ & & $\begin{array}{l}<0.0001^{*} \\
\text { n.s } \text { s }^{\#}\end{array}$ \\
\hline M AVA, $\mathrm{cm}^{2}$ & $0.7 \pm 0.2$ & $<0.0001^{*}$ & $0.8 \pm 0.2^{\#}$ & 0.130 & $0.8 \pm 0.1^{\#}$ & 0.108 & $\begin{array}{l}<0.0001^{*} \\
\text { n.s. }\end{array}$ \\
\hline F AVA, $\mathrm{cm}^{2}$ & $0.6 \pm 0.2$ & & $0.8 \pm 0.1^{\#}$ & & $0.7 \pm 0.1^{\#}$ & & $\begin{array}{l}<0.0001^{*} \\
\text { n.s } \text { s }^{\#}\end{array}$ \\
\hline M dPmean, mmHg & $51.3 \pm 11.7$ & $0.045^{*}$ & $29.0 \pm 7.0$ & 0.369 & $25.7 \pm 8.4$ & 0.822 & $<0.0001^{*}$ \\
\hline F dPmean, mmHg & $53.8 \pm 12.2$ & & $28.2 \pm 7.5$ & & $25.4 \pm 8.6$ & & $<0.0001^{*}$ \\
\hline M AVC, AU & 3076 [2211-3884] & $<0.0001^{*}$ & $1893[1085-2715]^{\#}$ & $<0.0001^{*}$ & $1644[1127-2639]^{\#}$ & $<0.0001^{*}$ & $\begin{array}{l}<0.0001^{*} \\
\text { n.s. }\end{array}$ \\
\hline $\mathrm{F}$ AVC, AU & 1785 [1237-2720] & & $1014[610-1666]^{\#}$ & & $1007[521-1547]^{\#}$ & & $\begin{array}{l}<0.0001^{*} \\
\text { n.s. }\end{array}$ \\
\hline M AVC density, $\mathrm{AU} / \mathrm{cm}^{2}$ & 551 [401-707] & $0.001 *$ & $333[216-481]^{\#}$ & $<0.0001^{*}$ & $322[220-490]^{\#}$ & $0.004^{*}$ & $\begin{array}{l}<0.0001^{*} \\
\text { n.s. }\end{array}$ \\
\hline $\mathrm{F}$ AVC density, $\mathrm{AU} / \mathrm{cm}^{2}$ & 424 [292-625] & & $244[144-389]^{\#}$ & & $230[123-340]^{\#}$ & & $\begin{array}{l}<0.0001^{*} \\
\text { n.s } \text { s }^{\#}\end{array}$ \\
\hline $\mathrm{M}$ NCC, $\mathrm{AU}$ & 1138 [737-1789] & $<0.0001 *$ & $703[424-1224]^{\#}$ & $<0.0001^{*}$ & $631[407-1086]^{\#}$ & $0.005^{*}$ & $\begin{array}{l}<0.0001^{*} \\
\text { n.s } \text { s }^{\#}\end{array}$ \\
\hline F NCC, AU & 751 [437-1228] & & $379[169-731]^{\#}$ & & $416[238-753]^{\#}$ & & $\begin{array}{l}<0.0001^{*} \\
\mathrm{n} . \mathrm{s}^{\#}\end{array}$ \\
\hline $\mathrm{M}$ NCC density, $\mathrm{AU} / \mathrm{cm}^{2}$ & 206 [134-308] & $0.045^{*}$ & $125[82-213]^{\#}$ & $<0.0001^{*}$ & $124[76-204]^{\#}$ & 0.121 & $\begin{array}{l}<0.0001^{*} \\
\mathrm{n} . \mathrm{s}^{\#}\end{array}$ \\
\hline $\mathrm{F}$ NCC density, $\mathrm{AU} / \mathrm{cm}^{2}$ & $175[97-288]$ & & $92[41-153]^{\#}$ & & $104[62-169]^{\#}$ & & $\begin{array}{l}<0.0001^{*} \\
\text { n.s } \text { s }^{\#}\end{array}$ \\
\hline $\mathrm{M}$ RCC, $\mathrm{AU}$ & 970 [493-1389] & $<0.0001 *$ & $495[246-844]^{\#}$ & $<0.0001^{*}$ & $538[296-832]^{\#}$ & $<0.0001^{*}$ & $\begin{array}{l}<0.0001^{*} \\
\text { n.s } \text { s }^{\#}\end{array}$ \\
\hline F RCC, AU & 534 [276-800] & & $280[151-519]^{\#}$ & & $232[103-382]^{\#}$ & & $\begin{array}{l}<0.0001^{*} \\
\text { n.s } \text { s }^{\#}\end{array}$ \\
\hline M RCC density, $\mathrm{AU} / \mathrm{cm}^{2}$ & 167 [98-244] & $<0.0001 *$ & $93[51-142]^{\#}$ & $0.003 *$ & $97[56-148]^{\#}$ & $<0.0001^{*}$ & $\begin{array}{l}<0.0001^{*} \\
\text { n.s } \text { s }^{\#}\end{array}$ \\
\hline $\mathrm{F}$ RCC density, $\mathrm{AU} / \mathrm{cm}^{2}$ & 126 [70-199] & & $68[34-115]^{\#}$ & & $52[27-78]^{\#}$ & & $\begin{array}{l}<0.0001^{*} \\
\text { n.s } \text { s }^{\#}\end{array}$ \\
\hline M LCC, AU & $822[521-1172]$ & $<0.0001^{*}$ & $456[264-7800]^{\#}$ & $<0.0001^{*}$ & $500[261-723]^{\#}$ & $<0.0001^{*}$ & $\begin{array}{l}<0.0001^{*} \\
\text { n.s } \text { s }^{\#}\end{array}$ \\
\hline F LCC, AU & $452[254-811]$ & & $244[131-442]^{\#}$ & & $208[97-428]^{\#}$ & & $\begin{array}{l}0.0003^{*} \\
\mathrm{n} . \mathrm{s}^{\#}\end{array}$ \\
\hline M LCC density, $\mathrm{AU} / \mathrm{cm}^{2}$ & $148[97-210]$ & $0.010^{*}$ & $83[48-151]^{\#}$ & $<0.0001^{*}$ & $96[51-131]^{\#}$ & $0.001^{*}$ & $\begin{array}{l}<0.0001^{*} \\
\text { n. } \text { s }^{\#}\end{array}$ \\
\hline F LCC density, AU/cm ${ }^{2}$ & 108 [59-182] & & $55[30-104]^{\#}$ & & $50[24-99]^{\#}$ & & $\begin{array}{l}<0.0001^{*} \\
\text { n. } \text { s }^{\#}\end{array}$ \\
\hline M LVOT, AU & $55[0-260]^{\#}$ & 0.761 & $33[0-151]^{\#}$ & 0.392 & $17[0-101]^{\#}$ & 0.759 & $\begin{array}{l}0.227 \\
\mathrm{n} . \mathrm{s}^{\#}\end{array}$ \\
\hline F LVOT, AU & $65[5-238]^{\#}$ & & $10[0-95]^{\#}$ & & $26[0-166]^{\#}$ & & $\begin{array}{l}0.544 \\
\text { n. } \text { s }^{\#}\end{array}$ \\
\hline M LVOT density, AU/cm² & $9[0-48]^{\#}$ & 0.235 & $6[0-27]^{\#}$ & 0.629 & $3[0-20]^{\#}$ & 0.589 & $\begin{array}{l}0.168 \\
\text { n.s } \text { s }^{\#}\end{array}$ \\
\hline F LVOT density, AU/ $/ \mathrm{cm}^{2}$ & $16[1-56]^{\#}$ & & $3[0-19]^{\#}$ & & $5[0-35]^{\#}$ & & $\begin{array}{l}0.582 \\
\text { n.s } \text { s }^{\#}\end{array}$ \\
\hline
\end{tabular}

Values are mean $\pm \mathrm{SD}$, median \pm interquartile range or $n(\%)$

$A V A$ aortic valve area, $A V C$ aortic valve calcification, $A U$ Agatston units, dPmean mean transvalvular gradient, $L C C$ left coronary cusp, $L V E F$ left-ventricular ejection fraction, $L V O T$ left-ventricular outflow tract, $N C C$ non-coronary cusp, $R C C$ right coronary cusp

$* p<0.05$

\#Detailed differences between groups as defined 
were consistently comparable in pLGAS (w/m: 1014 AU vs. $1893 \mathrm{AU} ; 244 \mathrm{AU} / \mathrm{cm}^{2}$ vs. $333 \mathrm{AU} / \mathrm{cm}^{2}$ ) and LGAS (w/m: $1007 \mathrm{AU}$ vs. $1644 \mathrm{AU} ; 230 \mathrm{AU} / \mathrm{cm}^{2}$ vs. $322 \mathrm{AU} /$ divided into several AS entities, NCC-calcium load performed best in women with HGAS and men with LGAS. In men with HGAS, RCC calcification performed even better.
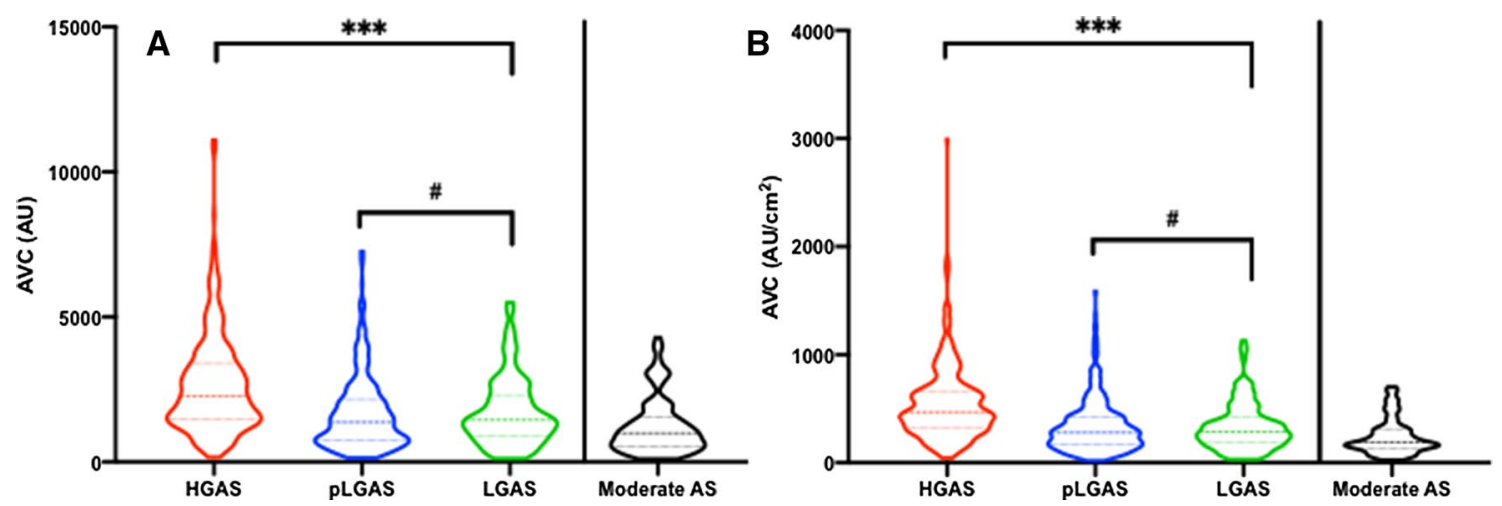

Fig. 2 Overall calcium distribution in several AS entities compared to moderate AS. a Total AVC in AU calculated in severe HGAS, pLGAS, and LGAS compared to moderate AS. b Calcium density $\left(\mathrm{AU} / \mathrm{cm}^{2}\right)$ proportions in severe HGAS, pLGAS, and LGAS compared to moderate AS

$\mathrm{cm}^{2}$ ), nearly achieving recommended AVC thresholds for severe AS. This is a new aspect, although several studies investigated the role of dis-concordant AS severity and AVC distribution [3, 10, 11]. If compared to overall moderate AS, c-statistics in HGAS revealed an AVC of $1292 \mathrm{AU}$ in women (c-index 0.85, 95\% CI 0.79-0.91; $p<0.0001 *$; sensitivity $62 \%$, specificity $93 \%$ ) and AVC of $2156 \mathrm{AU}$ in men (c-index $0.76,95 \%$ CI $0.65-0.79$; $p<0.0001 *$; sensitivity $65 \%$, specificity $79 \%$ ) or AVC density of $259 \mathrm{AU} / \mathrm{cm}^{2}$ in women (c-index $0.86,95 \%$ CI $0.81-0.92 ; p<0.0001 *$; sensitivity $80 \%$, specificity $80 \%$ ) and of $406 \mathrm{AU} / \mathrm{cm}^{2}$ in men (c-index $0.82,95 \% \mathrm{CI}$ $0.76-0.89 ; p<0.0001 *$; sensitivity $75 \%$, specificity $75 \%$ ) as the optimal threshold for diagnosis of severe AS. Concerning others' flow pattern, only AVC and leaflet calcification in men were able to differentiate between severe LGAS and moderate AS.

\section{The role of pronounced NCC calcification}

As mentioned before, the NCC was the most calcified cusp through all severity grades and AS entities. C-statistics depicted best coherence of NCC-calcium load with severity of AS in women (c-index $0.73-0.83$; 95\% CI 0.66-0.88; $p<0.0001^{*}$; sensitivity $70-77 \%$, specificity $73-80 \%$ ) if compared to male counterparts. In male patients, the LCC calcium load performed even better with best coherence concerning LCC density (c-index $0.82 ; 95 \%$ CI $0.74-0.89$; $p<0.0001^{*}$; sensitivity $84 \%$, specificity $70 \%$ ). Further
LCC calcification load revealed a comparable coherence in male patients with HGAS and LGAS, but only in women with HGAS. Concerning pLGAS, all AVC thresholds failed to differentiate between severe and moderate to borderline AS. Taken all these considerations into account, the best performance of NCC calcification thresholds under altered flow conditions might be a key factor in cases with predominating fibrosis, asymmetrical leaflet calcification, and borderline AVC in total. Pronounced NCC calcium load may be one of the first markers of underestimated AS in borderline conditions. To our knowledge, this is the first study, providing detailed information on leaflet calcification load in the context of AS severity and AS entities.

\section{The role of LVOT calcification}

Until now, the role of LVOT calcification has only been considered in the context of aortic regurgitation, conduction disturbances, and risk for other major adverse events in patients undergoing surgical and transcatheter aortic valve replacement $[12,13]$. According to practical experience, the amount of LVOT calcium load is often enhanced in severe and critical AS with an AVA $\leq 0.6 \mathrm{~cm}^{2}$. In our study, LVOT calcification was higher in in patients with HGAS but comparable between men and women throughout different AS entities. However, LVOT calcification may be higher in severe AS, but failed to be a reliable indicator for accelerating AS in this study. 
Table 3 Discrimination performance (ROC and AUC statistics) of severe AS entities in contrast to moderate AS

\begin{tabular}{|c|c|c|c|c|c|c|c|c|c|}
\hline Parameters & Entities & AUC & $p$ value & Lower 95\% CI & Upper $95 \%$ CI & Threshold & $\begin{array}{l}\text { Sensitiv- } \\
\text { ity }(\%)\end{array}$ & $\begin{array}{l}\text { Specific- } \\
\text { ity (\%) }\end{array}$ & LR \\
\hline \multicolumn{10}{|l|}{ Overall data } \\
\hline \multirow[t]{3}{*}{ AVC (AU) male } & HGAS & 0.76 & $<0.0001$ & 0.69 & 0.83 & $>2156$ & 65 & 79 & 3.1 \\
\hline & pLGAS & 0.62 & 0.0081 & 0.53 & 0.71 & $>1581$ & 63 & 62 & 1.7 \\
\hline & LGAS & 0.61 & 0.0348 & 0.51 & 0.70 & $>1589$ & 53 & 62 & 1.4 \\
\hline \multirow[t]{3}{*}{ AVC (AU) female } & HGAS & 0.85 & $<0.0001$ & 0.79 & 0.91 & $>1540$ & 62 & 93 & 9.0 \\
\hline & pLGAS & 0.66 & 0.0012 & 0.57 & 0.74 & $>1016$ & 50 & 73 & 1.8 \\
\hline & LGAS & 0.62 & 0.0425 & 0.51 & 0.74 & $>1012$ & 50 & 73 & 1.8 \\
\hline \multirow[t]{3}{*}{ AVC $\left(\mathrm{AU} / \mathrm{cm}^{2}\right)$ male } & HGAS & 0.82 & $<0.0001$ & 0.76 & 0.89 & $>406$ & 75 & 75 & 3.0 \\
\hline & pLGAS & 0.63 & 0.0050 & 0.54 & 0.72 & $>323$ & 52 & 72 & 1.8 \\
\hline & LGAS & 0.62 & 0.0196 & 0.54 & 0.72 & $>322$ & 51 & 72 & 1.8 \\
\hline \multirow[t]{3}{*}{ AVC $\left(\mathrm{AU} / \mathrm{cm}^{2}\right)$ female } & HGAS & 0.86 & $<0.0001$ & 0.81 & 0.92 & $>259$ & 80 & 80 & 3.9 \\
\hline & pLGAS & 0.66 & 0.0008 & 0.58 & 0.75 & $>192$ & 62 & 68 & 2.0 \\
\hline & LGAS & 0.63 & 0.00310 & 0.52 & 0.74 & $>180$ & 63 & 66 & 1.8 \\
\hline \multicolumn{10}{|l|}{ B) Adapted to LVF } \\
\hline \multirow[t]{3}{*}{ AVC (AU) male } & HGAS & 0.76 & $<0.0001$ & 0.68 & 0.85 & $>2156$ & 76 & 72 & 2.8 \\
\hline & pLGAS & 0.54 & 0.4108 & 0.44 & 0.65 & $>1754$ & 55 & 56 & 1.2 \\
\hline & LGAS & 0.79 & 0.0002 & 0.67 & 0.90 & $>1092$ & 78 & 76 & 3.3 \\
\hline \multirow[t]{3}{*}{ AVC (AU) female } & HGAS & 0.86 & $<0.0001$ & 0.80 & 0.93 & $>1137$ & 80 & 80 & 4.0 \\
\hline & pLGAS & 0.66 & 0.0022 & 0.57 & 0.75 & $>848$ & 58 & 63 & 1.6 \\
\hline & LGAS & 0.60 & 0.3580 & 0.40 & 0.79 & $>1012$ & 50 & 67 & 1.5 \\
\hline \multirow[t]{3}{*}{ AVC $\left(\mathrm{AU} / \mathrm{cm}^{2}\right)$ male } & HGAS & 0.78 & $<0.0001$ & 0.70 & 0.86 & $>506$ & 59 & 78 & 2.7 \\
\hline & pLGAS & 0.54 & 0.4314 & 0.44 & 0.65 & $>320$ & 53 & 61 & 1.4 \\
\hline & LGAS & 0.81 & $<0.0001$ & 0.71 & 0.92 & $>228$ & 75 & 88 & 6.4 \\
\hline \multirow[t]{3}{*}{ AVC $\left(\mathrm{AU} / \mathrm{cm}^{2}\right)$ female } & HGAS & 0.87 & $<0.0001$ & 0.81 & 0.93 & $>275$ & 80 & 83 & 4.6 \\
\hline & pLGAS & 0.67 & 0.0045 & 0.58 & 0.75 & $>178$ & 65 & 69 & 2.1 \\
\hline & LGAS & 0.63 & 0.2287 & 0.43 & 0.82 & $>231$ & 50 & 78 & 2.3 \\
\hline \multirow[t]{3}{*}{ NCC (AU) male } & HGAS & 0.70 & 0.0003 & 0.60 & 0.80 & $>1178$ & 50 & 78 & 2.2 \\
\hline & pLGAS & 0.53 & 0.6028 & 0.42 & 0.63 & $>656$ & 55 & 56 & 1.2 \\
\hline & LGAS & 0.77 & 0.0004 & 0.65 & 0.89 & $>370$ & 80 & 76 & 3.4 \\
\hline \multirow[t]{3}{*}{ NCC (AU) female } & HGAS & 0.81 & $<0.0001$ & 0.73 & 0.90 & $>491$ & 72 & 80 & 3.6 \\
\hline & pLGAS & 0.64 & 0.0074 & 0.54 & 0.74 & $>277$ & 63 & 63 & 1.7 \\
\hline & LGAS & 0.67 & 0.0985 & 0.48 & 0.87 & $>286$ & 65 & 78 & 2.9 \\
\hline \multirow[t]{3}{*}{$\mathrm{NCC}\left(\mathrm{AU} / \mathrm{cm}^{2}\right)$ male } & HGAS & 0.70 & 0.0002 & 0.61 & 0.80 & $>193$ & 56 & 78 & 2.5 \\
\hline & pLGAS & 0.52 & 0.6549 & 0.42 & 0.63 & $>114$ & 60 & 50 & 1.2 \\
\hline & LGAS & 0.77 & 0.0004 & 0.65 & 0.90 & $>63$ & 79 & 76 & 3.3 \\
\hline \multirow[t]{3}{*}{$\mathrm{NCC}\left(\mathrm{AU} / \mathrm{cm}^{2}\right)$ female } & HGAS & 0.83 & $<0.0001$ & 0.75 & 0.90 & $>115$ & 74 & 83 & 4.3 \\
\hline & pLGAS & 0.64 & 0.0075 & 0.42 & 0.63 & $>74$ & 60 & 69 & 1.9 \\
\hline & LGAS & 0.69 & 0.0660 & 0.49 & 0.90 & $>70$ & 63 & 78 & 2.8 \\
\hline \multirow[t]{3}{*}{ RCC (AU) male } & HGAS & 0.76 & $<0.0001$ & 0.67 & 0.85 & $>718$ & 66 & 78 & 2.9 \\
\hline & pLGAS & 0.55 & 0.6228 & 0.45 & 0.66 & $>415$ & 60 & 58 & 1.5 \\
\hline & LGAS & 0.72 & 0.0054 & 0.58 & 0.85 & $>157$ & 89 & 50 & 1.8 \\
\hline \multirow[t]{3}{*}{ RCC (AU) female } & HGAS & 0.82 & $<0.0001$ & 0.75 & 0.89 & $>324$ & 74 & 80 & 3.7 \\
\hline & pLGAS & 0.68 & 0.0010 & 0.58 & 0.77 & $>192$ & 71 & 60 & 1.8 \\
\hline & LGAS & 0.51 & 0.9042 & 0.28 & 0.75 & $<249$ & 54 & 67 & 1.6 \\
\hline \multirow[t]{5}{*}{$\mathrm{RCC}\left(\mathrm{AU} / \mathrm{cm}^{2}\right)$ male } & HGAS & 0.77 & $<0.0001$ & 0.69 & 0.86 & $>149$ & 60 & 75 & 2.4 \\
\hline & pLGAS & 0.54 & 0.4473 & 0.43 & 0.65 & $>76$ & 63 & 61 & 1.6 \\
\hline & LGAS & 0.72 & 0.0054 & 0.58 & 0.85 & $>42$ & 81 & 59 & 2.0 \\
\hline & pLGAS & 0.67 & 0.0018 & 0.57 & 0.76 & $>52$ & 63 & 63 & 1.7 \\
\hline & LGAS & 0.53 & 0.7677 & 0.65 & 0.90 & $<60$ & 56 & 67 & 1.7 \\
\hline
\end{tabular}


Table 3 (continued)

\begin{tabular}{|c|c|c|c|c|c|c|c|c|c|}
\hline Parameters & Entities & AUC & $p$ value & Lower 95\% CI & Upper 95\% CI & Threshold & $\begin{array}{l}\text { Sensitiv- } \\
\text { ity (\%) }\end{array}$ & $\begin{array}{l}\text { Specific- } \\
\text { ity (\%) }\end{array}$ & LR \\
\hline \multirow[t]{3}{*}{ LCC (AU) male } & HGAS & 0.75 & $<0.0001$ & 0.66 & 0.85 & $>427$ & 81 & 67 & 2.4 \\
\hline & pLGAS & 0.57 & 0.2068 & 0.46 & 0.67 & $>423$ & 53 & 67 & 1.6 \\
\hline & LGAS & 0.73 & 0.0032 & 0.60 & 0.85 & $>331$ & 63 & 71 & 2.2 \\
\hline \multirow[t]{3}{*}{ LCC (AU) female } & HGAS & 0.78 & $<0.0001$ & 0.70 & 0.86 & $>319$ & 64 & 83 & 3.8 \\
\hline & pLGAS & 0.60 & 0.0621 & 0.50 & 0.70 & $>230$ & 52 & 60 & 1.3 \\
\hline & LGAS & 0.52 & 0.8869 & 0.32 & 0.71 & $>211$ & 50 & 67 & 1.5 \\
\hline \multirow[t]{3}{*}{$\mathrm{LCC}\left(\mathrm{AU} / \mathrm{cm}^{2}\right) \mathrm{male}$} & HGAS & 0.76 & $<0.0001$ & 0.67 & 0.85 & $>98$ & 75 & 69 & 2.5 \\
\hline & pLGAS & 0.57 & 0.2100 & 0.46 & 0.67 & $>74$ & 58 & 53 & 1.2 \\
\hline & LGAS & 0.75 & 0.0012 & 0.63 & 0.86 & $>40$ & 84 & 53 & 1.8 \\
\hline \multirow[t]{3}{*}{$\mathrm{LCC}\left(\mathrm{AU} / \mathrm{cm}^{2}\right)$ female } & HGAS & 0.78 & $<0.0001$ & 0.70 & 0.86 & $>67$ & 73 & 77 & 3.2 \\
\hline & pLGAS & 0.60 & 0.0680 & 0.50 & 0.69 & $>52$ & 54 & 57 & 1.3 \\
\hline & LGAS & 0.54 & 0.7262 & 0.35 & 0.72 & $>46$ & 54 & 67 & 1.6 \\
\hline
\end{tabular}

$A V A$ aortic valve area, $A V C$ aortic valve calcification, $A U$ Agatston units, $A U C$ area under the curve, $L V O T$ left-ventricular outflow tract, $N C C$ non-coronary cusp, $R C C$ right coronary cusp

$* p<0.05$

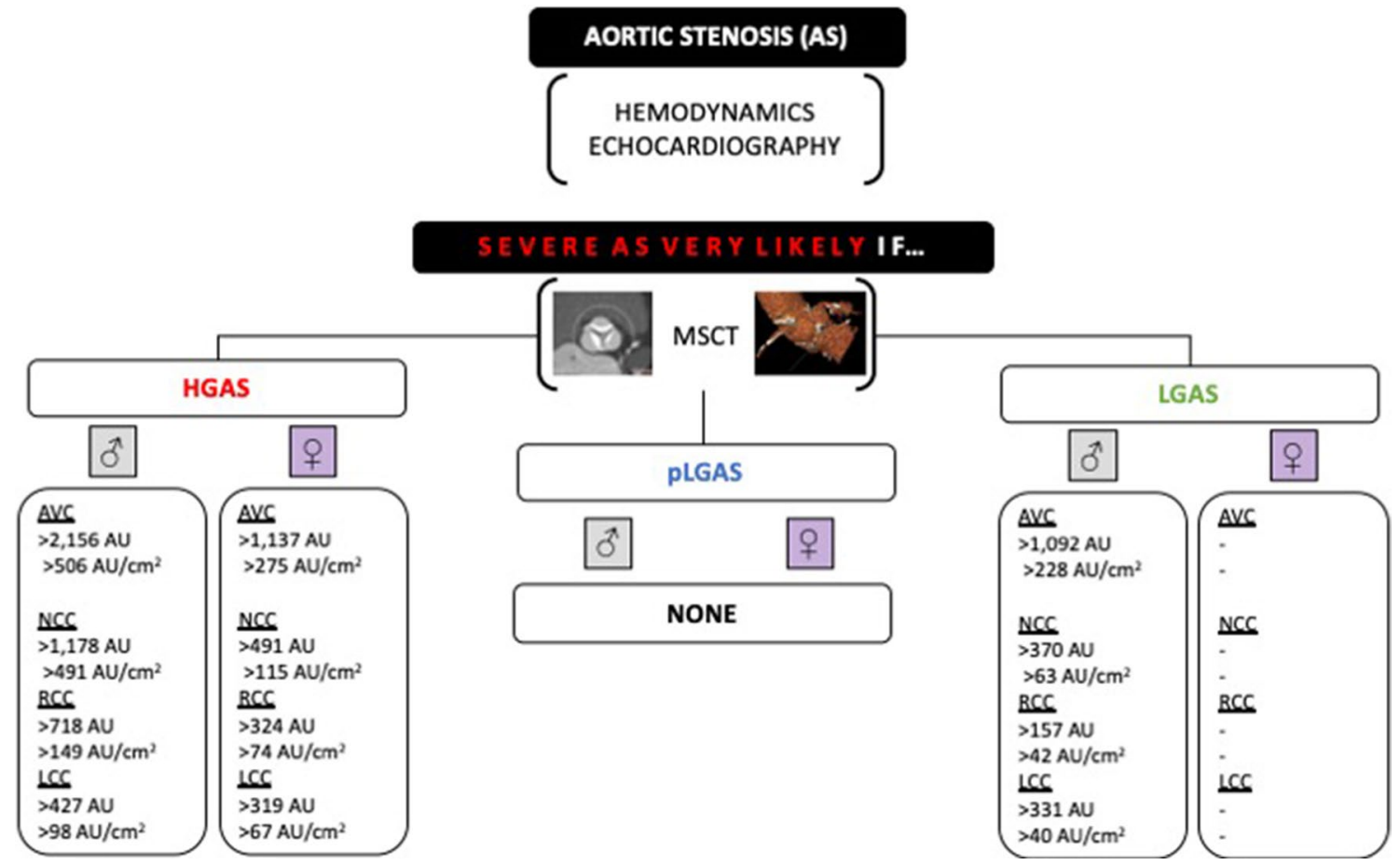

Fig. 3 Graphical abstract-using Aortic valve calcium scoring for an individualized diagnostic severity tool in different AS entities. Primary assessment of severity and hemodynamics by echocardiog- raphy. Further discrimination into several AS entities according to current recommendations. MSCT-derived AVC can provide complementary assessment of disease severity in several AS entities 


\section{Conclusion}

Data from this retrospective analysis indicate that the NCC shows predominating degeneration throughout gender, AS severity, and several AS entities. AVC was comparable in severe pLG and LGAS, but only AVC in severe LGAS could sufficiently distinguish moderate from severe AS in men. LVOT calcification failed to be a reliable indicator of accelerating AS.

\section{Limitations}

This study is a single-center, retrospective analysis which is underpowered in regards of low-flow entities and, therefore, a meaningful interpretation of reliable AVC thresholds in these sub-cohorts may not be possible. AS hemodynamics is subject to several influencing factors such as blood pressure, volume status, and the underlying heart rhythm (atrial fibrillation vs sinus rhythm vs paced rhythm). A confounding factor is the small anatomy in women, which may be addressed by exclusion of increased LVOT flow and energy loss index in a small anatomy.

Acknowledgements We thank Jenni Scharlau for substantial contribution in data acquisition.

Funding Open Access funding provided by Projekt DEAL. None.

\section{Compliance with ethical standards}

Conflict of interest Verena Veulemans, Tobias Zeus, Amin Polzin, Christian Jung, and Ralf Westenfeld have received consulting fees, travel expenses, or study honoraries from Medtronic and Edwards Lifesciences. All other authors have nothing to disclose with regard to this project.

Open Access This article is licensed under a Creative Commons Attribution 4.0 International License, which permits use, sharing, adaptation, distribution and reproduction in any medium or format, as long as you give appropriate credit to the original author(s) and the source, provide a link to the Creative Commons licence, and indicate if changes were made. The images or other third party material in this article are included in the article's Creative Commons licence, unless indicated otherwise in a credit line to the material. If material is not included in the article's Creative Commons licence and your intended use is not permitted by statutory regulation or exceeds the permitted use, you will need to obtain permission directly from the copyright holder. To view a copy of this licence, visit http://creativecommons.org/licenses/by/4.0/.

\section{References}

1. Nkomo VT, Gardin JM, Skelton TN, Gottdiener JS, Scott CG, Enriquez-Sarano M (2006) Burden of valvular heart diseases: a population-based study. Lancet 368:1005-1011
2. Messika-Zeitoun D, Aubry MC, Detaint D, Bielak LF, Peyser PA, Sheedy PF, Turner ST, Breen JF, Scott C, Tajik AJ, EnriquezSarano M (2004) Evaluation and clinical implications of aortic valve calcification measured by electron-beam computed tomography. Circulation 110:356-362

3. Cueff C, Serfaty JM, Cimadevilla C, Laissy JP, Himbert D, Tubach F, Duval X, Iung B, Enriquez-Sarano M, Vahanian A, MessikaZeitoun D (2011) Measurement of aortic valve calcification using multislice computed tomography: correlation with haemodynamic severity of aortic stenosis and clinical implication for patients with low ejection fraction. Heart 97:721-726

4. Clavel MA, Messika-Zeitoun D, Pibarot P, Aggarwal SR, Malouf J, Araoz PA, Michelena HI, Cueff C, Larose E, Capoulade R, Vahanian A, Enriquez-Sarano M (2013) The complex nature of discordant severe calcified aortic valve disease grading: new insights from combined Doppler echocardiographic and computed tomographic study. J Am Coll Cardiol 62(24):2329-2338

5. Aggarwal SR, Clavel MA, Messika-Zeitoun D, Cueff C, Malouf J, Araoz PA, Mankad R, Michelena H, Vahanian A, EnriquezSarano M (2013) Sex differences in aortic valve calcification measured by multidetector computed tomography in aortic stenosis. Circ Cardiovasc Imaging 6:40-47

6. Baumgartner H, Falk V, Bax JJ, De Bonis M, Hamm C, Holm PJ, Iung B, Lancellotti P, Lansac E, Rodriguez Muñoz D, Rosenhek R, Sjögren J, Tornos Mas P, Vahanian A, Walther T, Wendler O, Windecker S, Zamorano JL, ESC Scientific Document Group (2017) ESC/EACTS Guidelines for the management of valvular heart disease. Eur Heart J 38:2739-2786

7. Achenbach S, Delgado V, Hausleiter J, Schoenhagen P, Min JK, Leipsic JA (2012) SCCT expert consensus document on computed tomography imaging before transcatheter aortic valve implantation (TAVI)/transcatheter aortic valve replacement (TAVR). J Cardiovasc Comput Tomogr 6:366-380

8. Alqahtani AM, Boczar KE, Kansal V, Chan K, Dwivedi G, Chow BJ (2017) Quantifying aortic valve calcification using coronary computed tomography angiography. J Cardiovasc Comput Tomogr 11:99-104

9. Chetcuti SJ, Deeb GM, Popma JJ, Yakubov SJ, Grossman PM, Patel HJ, Casale A, Dauerman HL, Resar JR, Boulware MJ, DriesDevlin JL, Li S, Oh JK, Reardon MJ (2019) Self-expanding transcatheter aortic valve replacement in patients with low-gradient aortic stenosis. JACC Cardiovasc Imaging 12:67-80

10. Pawade T, Clavel MA, Tribouilloy C, Dreyfus J, Mathieu T, Tastet L, Renard C, Gun M, Jenkins WSA, Macron L, Sechrist JW, Lacomis JM, Nguyen V, Galian Gay L, Cuéllar Calabria H, Ntalas I, Cartlidge TRG, Prendergast B, Rajani R, Evangelista A, Cavalcante JL, Newby DE, Pibarot P, Messika Zeitoun D, Dweck MR (2018) Computed tomography aortic valve calcium scoring in patients with aortic stenosis. Circ Cardiovasc Imaging 11:e007146

11. Pawade T, Sheth T, Guzzetti E, Dweck MR, Clavel MA (2019) Why and how to measure aortic valve calcification in patients with aortic stenosis. JACC Cardiovasc Imaging 12:1835-1848

12. Latsios G, Gerckens U, Buellesfeld L, Mueller R, John D, Yuecel S, Syring J, Sauren B, Grube E (2010) "Device landing zone" calcification, assessed by MSCT, as a predictive factor for pacemaker implantation after TAVI. Catheter Cardiovasc Interv 76:431-439

13. Maeno Y, Abramowitz Y, Kawamori H, Kazuno Y, Kubo S, Takahashi N, Mangat G, Okuyama K, Kashif M, Chakravarty T, Nakamura M, Cheng W, Friedman J, Berman D, Makkar RR, Jilaihawi H (2017) A highly predictive risk model for pacemaker implantation after TAVR. JACC Cardiovasc Imaging 10:1139-1147

Publisher's Note Springer Nature remains neutral with regard to jurisdictional claims in published maps and institutional affiliations. 